\title{
Energy storage using underground mining caverns
}

\author{
Eukasz Szabłowski ${ }^{1,}{ }^{*}$, Piotr Krawczyk ${ }^{1}$, and Krzysztof Badyda $^{1}$ \\ ${ }^{1}$ Institute of Heat Engineering, Warsaw University of Technology, Nowowiejska 21/25, 00-665 \\ Warsaw, Poland
}

\begin{abstract}
In recent years, due to the very intensive development of renewable sources (working in a very irregular and unpredictable way), energy storage has acquired a special importance for the stability of the power system. There are many methods of energy storage, but only two have adequate capacity and power: Pumped Hydro Storage (PHS) and Compressed Air Energy Storage (CAES). The article presents energy analysis of energy storage system based on compressed air inside underground mining caverns. A dynamic mathematical model of CAES system of parameters and structure similar to the Huntorf type power plant was constructed. Filling and emptying of the cavern with compressed air was numerically simulated. Balance calculations for selected configuration of the system was performed. Four different equations were used to describe the efficiency of the storage.
\end{abstract}

\section{Introduction}

Technology of power plants with underground compressed air storage is based on solutions which are well known and have been proven either in power industry or in oil \& gas business. Those solutions are also well known in Poland, at least from the operational side. Gas turbines for CAES (Compressed Air Energy Storage) plants are based on adapted (extended with necessary components) standard solutions for power industry. Compressor systems are based on solutions known from power industry (axial compressors), complemented with units proven during years of operation in other branches of industry (high pressure centrifugal air compressors).

Available publications mention two practicable methods of underground air storage: constant pressure and constant volume. These are alternatively known as wet storage and dry storage respectively, or sometimes also as air storage in vessels with and without compensation. In a constant volume solution, the storage operates at predetermined range of pressures.

The upper limit is determined by geological conditions, primarily due to the need to ensure airtightness (specified as permissible air loss) during operation. The lower limit is determined by permissible operating conditions of power plant equipment supplied from the storage. Both pressure values combined with the available volume determine amount of air

\footnotetext{
* Corresponding author: 1szablow@itc.pw.edu.pl
} 
which may be stored. The already mentioned alternative solution is a system with hydraulic compensation. This solution requires an air storage space within a hard rock and use of a water reservoir, natural or artificial. In this case, change of air volume in the storage space is caused by change of level of liquid used to flood it. As opposed to the constant volume solution, the depth at which the air reservoir is located must be correlated to the compressor operating parameters. Maximum compressor operating pressure must ensure ability to inject the air under the pressure of column of water pushed out of the reservoir.

A CAES power plant consumes low priced off-peak electricity, for example during nights and weekends. This electricity is used to compress air subsequently stored in huge reservoirs. Compressed air accumulation is based on six decades of experience, including Polish, with underground gas storage. Due to the huge amount of needed air and resulting financial constraints, it may be assumed that only use of natural reservoirs is feasible. Possible options include salt caverns and formations with aquifers, as well as exhausted mines of salt, limestone or other materials set in hard rock structure [1-3].

Due to the limited volume of even larger reservoirs, the storage pressure must be relatively high. The maximum value should be noticeably higher than the one required for the combustor of the gas turbine used in the system. Also the minimum value used in the storage cycle should exceed the level required for the combustor.

Electricity production is started when the power demand is high.

The air is released from the reservoir and expanded in a turbine. Due to the high required compression levels resulting from the conditions described above, intercooling is needed in a CAES plant. Additionally, it is also needed to maintain sufficiently low temperature of the air injected into reservoir (with compressor intercoolers and aftercooler). Just like in case of natural gas storage, the air is cooled to the temperature of some $40-50^{\circ} \mathrm{C}$. This protects from the impact of high temperatures on piping and borehole casing. Another restriction results from the fact that the reservoir's storage capacity diminishes as the temperature of the stored air grows.

The advantage of compressed air storage compared to natural gas storage, is its ability to drive a standalone gas turbine during the expansion process.

Thanks to this the generator output is not restricted by a necessity to drive a compressor at the same time. In a power balance of a large output classic gas turbine unit (compressorcombustor-turbine), compressor drive claims more than $50 \%$ of turbine output. Time separation of compression and expansion means, that the turbine may give much higher output than what is needed to drive a compressor in a classic system. Possibility to perform the compression process over longer time allows further increase of difference between the power consumed (by the compressor) and produced (by the turbine).

CAES technology is relatively well known. Currently there are two major facilities of this type in the world: Huntorf in Germany (capacity of $290 \mathrm{MW}$ ) and McIntosh in the USA (capacity of $110 \mathrm{MW}$ ). The former was commissioned in 1978, the latter in 1991. Figure 1 presents a comparison of the Huntorf facility and its both caverns. 


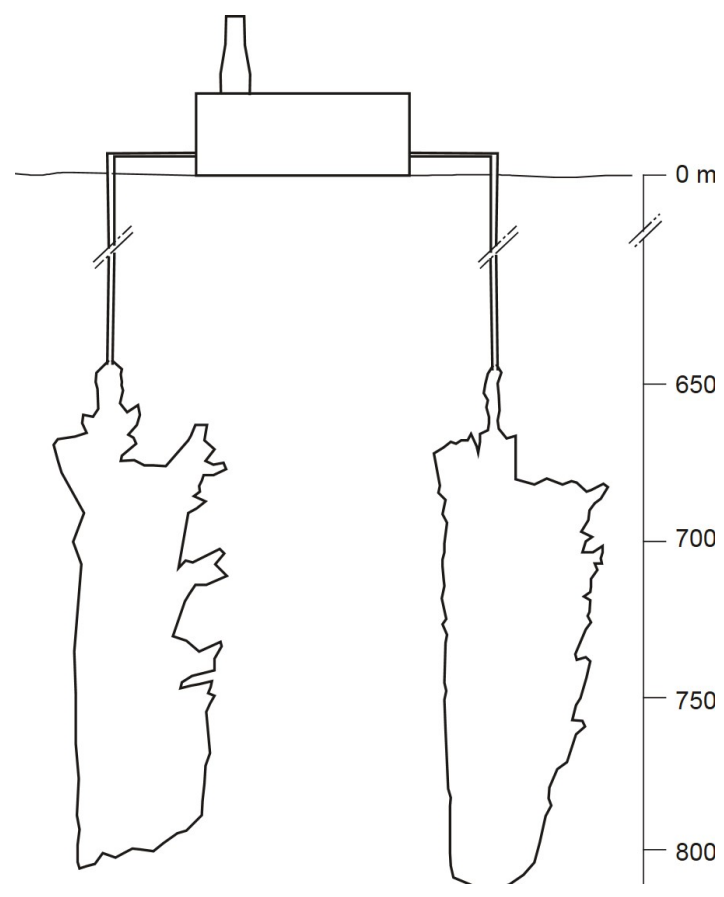

Fig. 1. Comparison of sizes of the Huntorf Power Plant and its two caverns [4].

There are potential sites for compressed air storage facilities in Poland too.

The main difficulties involve identification of a proper site, and potentially lengthy project construction phase, due to the need to adapt the air reservoir for storage operation, as well as delivery of equipment, which would at least partially consist of custom-designed products.

Some sites can be preselected, for example using research concerning potential carbon dioxide storage facilities, which has a similar goal. Such works have been carried out for example within the CASTOR project [5]. The most favourable geological structure conditions may be found in the north-western and central parts of Poland.

Outside northern part of the country, locations worth consideration include large salt deposits in the area of Legnica-Głogów Copper District, in the copper-bearing part of the Sudetian Monocline. In this area it would be possible to leach salt caverns with following properties:

- cylindrical shape, diameter of $64 \mathrm{~m}$, height of $120 \mathrm{~m}$,

- active geometrical volume of $350000 \mathrm{~m}^{3}$,

- maximum chamber pressure $20 \mathrm{MPa}$,

- minimum chamber pressure $4 \mathrm{MPa}$.

Those dimensions are close to those at the Huntorf facility [4], which model is presented later in this article (Section 3 and following).

Current state of knowledge on CAES technology is presented in studies [6-10]. Methods for determining efficiency for diabatic CAES systems are presented in [11].

A hybrid system combining CAES and renewable technologies (CAES-RT) is discussed in [1]. The same paper presents a possibility of creating such a facility in Poland. A dynamic mathematical model of a CAES system is presented in [1-3].

Publication [12] presents a simulation and thermodynamic analysis of a Compressed Air Energy Storage-Combined Cycle (CAES-CC) system proposed by its authors. Efficiency of this solution is some $10 \%$ higher than of classical CAES. The reference CAES in this case was a system without regeneration. According to the authors, the heat recovered from the 
intercoolers during air compression (storage charging phase) may be used for maintaining the steam cycle in hot standby.

Paper [13] presents a system consisting of a CAES plant and Kalina cycle for waste heat recovery. This combination yielded an efficiency increase of $4 \%$ compared to standalone CAES. In this case the reference CAES plant did have regeneration.

Analysis of influence of selected parameters (pressure ratio, ambient air temperature, air mass flow) on performance of adiabatic CAES system is presented in [14]. Calculations were based on a silent assumption that the system is of a constant pressure type.

[15] discusses a thermodynamic analysis of an adiabatic CAES with solid heat storage. Application of such a storage unit allowed reaching efficiency within 70.5-71.1\% range. Maximum temperature in the storage was $440^{\circ} \mathrm{C}$ (for a 2-stage system).

A completely different approach is presented in [16] which deals with a concept of a lowtemperature adiabatic CAES system. It achieved storage efficiency within 52-60\%, with a maximum temperature in heat storage of $200^{\circ} \mathrm{C}$. This solution required using storage of cold (created during expansion) as well. According to the authors, this arrangement enables using cheaper components and achieving start-up time below 5 minutes.

[17] discusses an analysis of an off-design point operation of CAES integrated with a hybrid power station, and additionally combined with a wind power plant. A one-year operation of such a plant at an Italian energy market was simulated. Cost analysis was performed using thermal-economic approach.

The study [18] presents a concept of a small CAES system cooperating with photovoltaic panels to supply a base station of mobile telephony network. This system was integrated with a storage of heat generated during air compression and consumed during expansion in turbine. Additional functionality of this solution was cooling generation, as the temperature of air exhausted from the turbine was $3^{\circ} \mathrm{C}$. Despite small scale of the facility, the energy storage efficiency was $57 \%$.

Studies $[19,20]$ presented a hybrid system combining a CAES part and LAES (liquid air energy storage) module. This system was capable of converting compressed air (50 bar) at the ambient air temperature, to a liquid air at ambient air pressure. The system would also be capable of reversing this process. According to the authors $[19,20]$ this solution would be cheaper than either LAES or CAES (when using artificial compressed air vessels). Preliminary analysis [19] yielded a calculated system efficiency of 53\%, however follow-up analysis [20] reduced that value to $42 \%$.

In [21] the influence of selected parameters on the adiabatic LAES performance was shown. A comparison of CAES and LAES systems and exergy analysis of their operation was presented in [22]. While the exergy analysis of adiabatic CAES system was described in [23]. An overview of various CAES technologies can be seen in [24].

\section{Methods}

Calculations presented in this paper have been performed using commercial software [25, 26]. Dynamic calculations of physical phenomena are described with linear and non-linear differential equations, which may be found in [27]. Therefore only essential equations are presented in this section.

Mass flow of the working medium through a valve is described with a following equation:

$$
\dot{\mathrm{m}}=\mathrm{Cv} \sqrt{\Delta \mathrm{p}}
$$

where $\dot{\mathrm{m}}$ is mass flow; $C v$ is coefficient representing inversion of flow resistance (conductivity); $\Delta \mathrm{p}$ is pressure drop at the valve.

The essential equation describing valve properties includes the $\mathrm{Cv}$ coefficient, as well as pressure drop across the valve attributable to flow resistance.

$$
\dot{\mathrm{m}}=\mathrm{f}\left(\mathrm{Cv}, \mathrm{p}_{1}, \mathrm{p}_{2}\right)
$$


where $\dot{\mathrm{m}}$ is mass flow; $C v$ is coefficient representing inversion of flow resistance (conductivity); $p_{1}$ and $p_{2}$ are pressure of supplied medium and outlet medium pressure.

Relation describing heat transfer within the shell of a heat exchanger (of shell and tube type):

$$
\dot{\mathrm{m}}_{\text {shell }} \cdot\left(\mathrm{h}_{\text {in }}-\mathrm{h}_{\text {out }}\right)_{\text {shell }}-\mathrm{Q}_{\text {loss }}+\mathrm{Q}=\rho \frac{\mathrm{d}\left(\mathrm{V} \cdot \mathrm{h}_{\text {out }}\right)_{\text {shell }}}{\mathrm{dt}}
$$

Relation describing heat transfer within the tubes of a heat exchanger:

$$
\dot{\mathrm{m}}_{\text {tube }} \cdot\left(\mathrm{h}_{\mathrm{in}}-\mathrm{h}_{\text {out }}\right)_{\text {tube }}-\mathrm{Q}=\rho \frac{\mathrm{d}\left(\mathrm{V} \cdot \mathrm{h}_{\text {out }}\right)_{\text {tube }}}{\mathrm{dt}}
$$

where $\dot{\mathrm{m}}_{\text {shell }}$ and $\dot{m}_{\text {tube }}$ are mass flows of the working medium within the shell and tube of a heat exchanger; $\rho$ is density; $h$ is enthalpy of the working medium; $Q$ is heat transfer between the shell and tubes of a heat exchanger; $Q_{\text {loss }}$ are heat losses; $V$ is volume of the medium contained in the shell or tubes; $t$ is time.

Both isentropic and polytropic power of a compressor or turbine may be calculated using relation (5).

$$
\mathrm{P}=\dot{\mathrm{n}}_{1} \cdot \mathrm{M} \cdot\left(\frac{\mathrm{n}}{\mathrm{n}-1}\right) \cdot \mathrm{CF} \cdot\left(\frac{\mathrm{p}_{1}}{\rho_{1}}\right)\left[\left(\frac{\mathrm{p}_{2}}{\mathrm{p}_{1}}\right)^{\left(\frac{\mathrm{n}-1}{\mathrm{n}}\right)}-1\right]
$$

where $n$ is polytropic or isentropic index; $C F$ is correction factor; $p_{1}$ and $p_{2}$ are inlet and outlet pressures; $\rho_{l}$ is inlet density of the medium; $\dot{\mathrm{n}}_{1}$ is inlet molar flow; $M$ is molar mass of the working medium.

The correction coefficient is expressed by the following equation:

$$
\mathrm{CF}=\frac{\mathrm{h}^{\prime}{ }_{2}-\mathrm{h}_{1}}{\left(\frac{\mathrm{n}}{\mathrm{n}-1}\right)\left(\frac{\mathrm{p}_{2}}{\rho^{\prime}}{ }_{2}-\frac{\mathrm{p}_{1}}{\rho_{1}}\right)}
$$

where $h_{2}^{\prime}$ is exhaust working medium enthalpy for isentropic process; $h_{l}$ is inlet working medium enthalpy.

Power transferred to the working agent by the compressor can be represented by the following formula:

$$
\mathrm{P}_{1-2}=\dot{\mathrm{n}}_{1} \cdot \mathrm{M} \cdot\left(\mathrm{h}_{2}-\mathrm{h}_{1}\right)
$$

where $\dot{\mathrm{n}}_{1}$ is inlet molar flow of the working medium; $h_{2}$ and $h_{l}$ are outlet and inlet working medium enthalpy; $M$ is molar mass of the working medium.

Power recovered from the working medium in the turbine is expressed by the following relation:

And moment of inertia:

$$
\mathrm{P}_{1-2}=\dot{\mathrm{n}}_{1} \cdot \mathrm{M} \cdot\left(\mathrm{h}_{1}-\mathrm{h}_{2}\right)
$$

$$
\mathrm{I}=\mathrm{m} \cdot \mathrm{R}^{2}
$$

where $m$ is mass of rotating elements; $\mathrm{R}$ is equivalent radius of the rotor parts.

Power needed to change speed of rotation:

where $\omega$ is angular velocity; $t$ is time..

$$
P_{I}=I|\omega| \frac{d \omega}{d t}
$$

There are several ways to describe the energy storage efficiency in CAES systems. Four of them are shown below [1-3]:

$$
\begin{aligned}
& \eta_{\text {CAES I }}=\frac{E_{\text {elg }}}{E_{\text {el c }}+Q_{f}} \\
& \eta_{\text {CAES II }}=\frac{E_{\text {el g }}-E_{\text {el c }}}{Q_{f}} \\
& \eta_{\text {CAES III }}=\frac{E_{\text {elg }}}{\frac{E_{\text {elc }}}{\eta_{\text {elR }} \cdot \eta_{\text {tr }}}+Q_{\mathrm{f}}} \\
& \eta_{\text {CAES IV }}=\frac{1-H R \cdot \eta_{\text {gas }}}{\text { ER }_{\text {net }}}
\end{aligned}
$$

where $E_{\text {elg }}$ is generator energy output; $E_{\text {el c }}$ is compressor energy consumption; $Q_{f}$ is fuel chemical energy; $\eta_{e l R}$ is reference power plant efficiency ( $42 \%$ used in this paper); $\eta_{t r}$ is efficiency of electricity transmission to CAES plant (assumed 90\%); $H R$ is heat rate of the 
standalone gas turbine (in $\mathrm{kJ} / \mathrm{kJ}$ ); $\eta_{\text {gas }}$ is efficiency of chemical energy to electricity conversion (36.9\% - for the simple cycle gas turbine heat rate of $9743 \mathrm{~kJ} / \mathrm{kWh} \mathrm{[28]).}$

Relation (14) is less frequently used - more information about it may be found in [28].

\section{Model description}

The model has been built in Aspen HYSYS software. Properties of used media were described using the Peng-Robinson model. Mass composition of air supplied to the compressor is given in Table 1 . This air composition corresponds to $60 \%$ of relative humidity. Fuel used in the system was methane with a lower heating value of $50035 \mathrm{~kJ} / \mathrm{kg}$.

Table 1. Composition of air by weight.

\begin{tabular}{|c|c|}
\hline Component & \%-wt \\
\hline $\mathrm{O}_{2}$ & 23.052 \\
\hline $\mathrm{N}_{2}$ & 74.99 \\
\hline $\mathrm{CO}_{2}$ & 0.046 \\
\hline $\mathrm{Ar}$ & 1.276 \\
\hline $\mathrm{H}_{2} \mathrm{O}$ & 0.636 \\
\hline
\end{tabular}

Diagram of the proposed CAES system is shown in Figure 2. Polytropic efficiencies of the rotating machinery (turbines and compressors) were preset at $75 \%$. Cavern volume is $310000 \mathrm{~m}^{3}$, and normal operating pressures are from 43 to 70 bar. Each of the intercoolers reduces the air temperature to $50^{\circ} \mathrm{C}$ and also decreases its pressure by 0.1 (IC1) and 0.5 bar (IC2) at nominal operation of the system (these values change as the air mass flow changes). Cooling water has a temperature of $15^{\circ} \mathrm{C}$.and pressure of 2 bar at the inlet. Outlet parameters are $75^{\circ} \mathrm{C}$. and 1.9 bar. The compressor is split into 2 parts, each with a power demand of 30 MW during charging. Heat generated in the process by compressors is lost to the environment. Temperatures of working medium leaving first and second combustion chambers are 550 and $825^{\circ} \mathrm{C}$ respectively. Pressure after the first turbine was assumed to be 22 bar. The V2 valve is controlled in such a way, that a constant flow value $(416 \mathrm{~kg} / \mathrm{s})$ is preserved during discharging. Leakage losses the caverns and the system were omitted

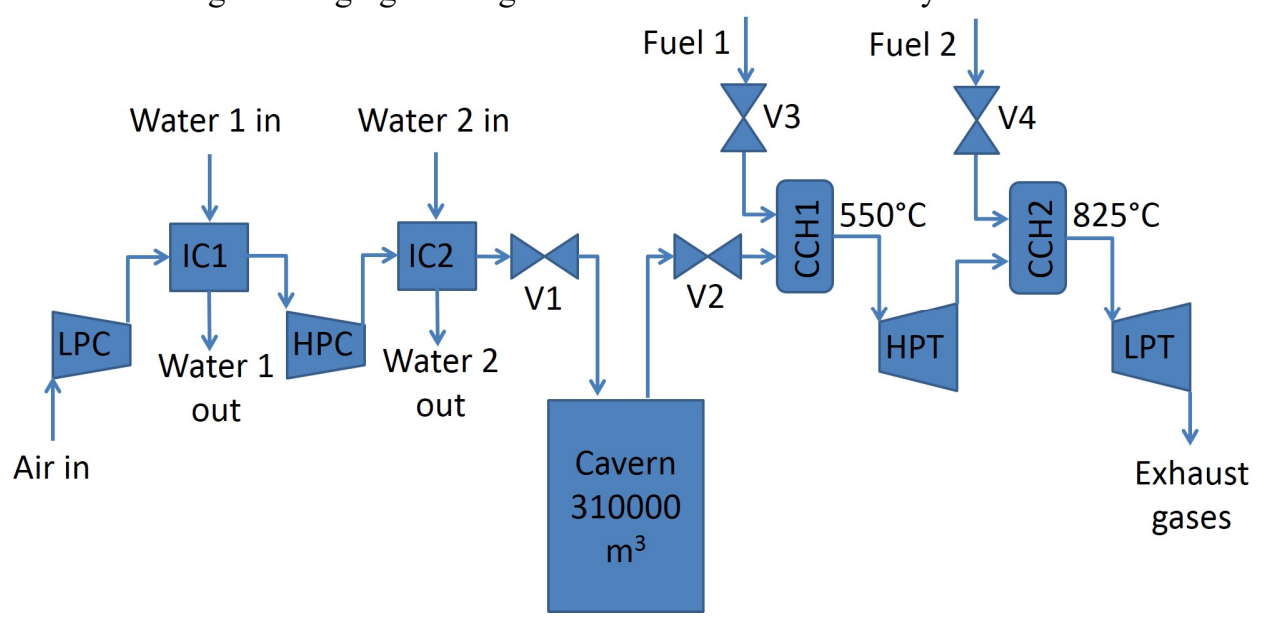

Fig. 2. Diagram of the modelled CAES system. 


\section{Results}

Figure 3 presents changes of pressure inside the cavern and injected air mass flow during charging.

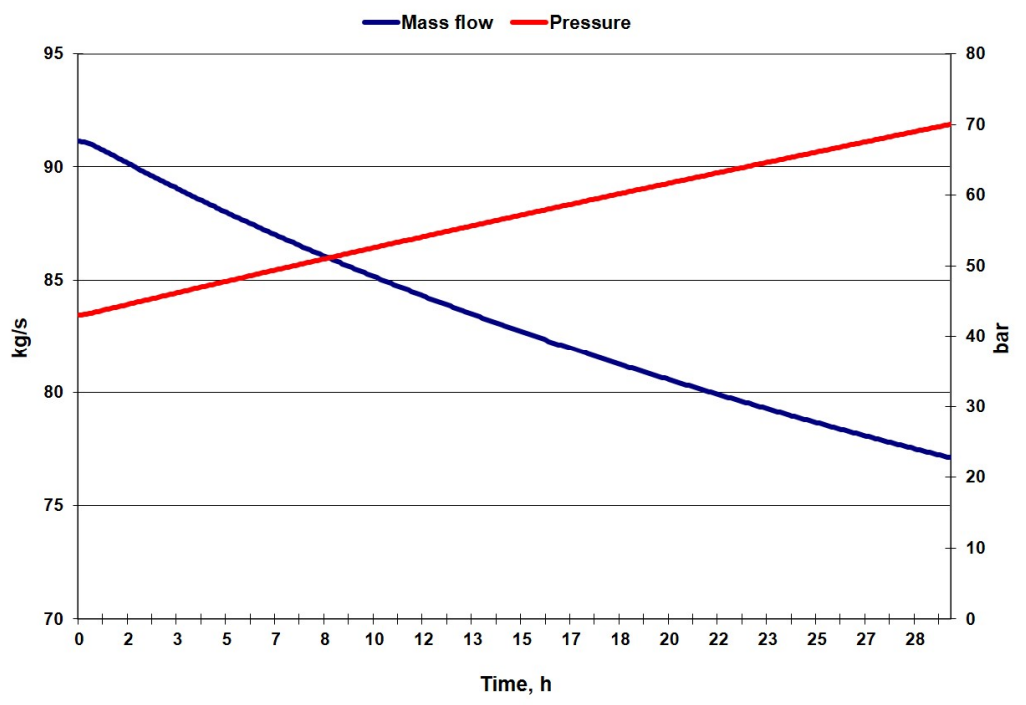

Fig. 3. Changes of pressure inside the cavern and injected air mass flow during charging.

The Figure 4 illustrates the mass flow of air released from the cavern during discharging, and the position of the V2 control valve.

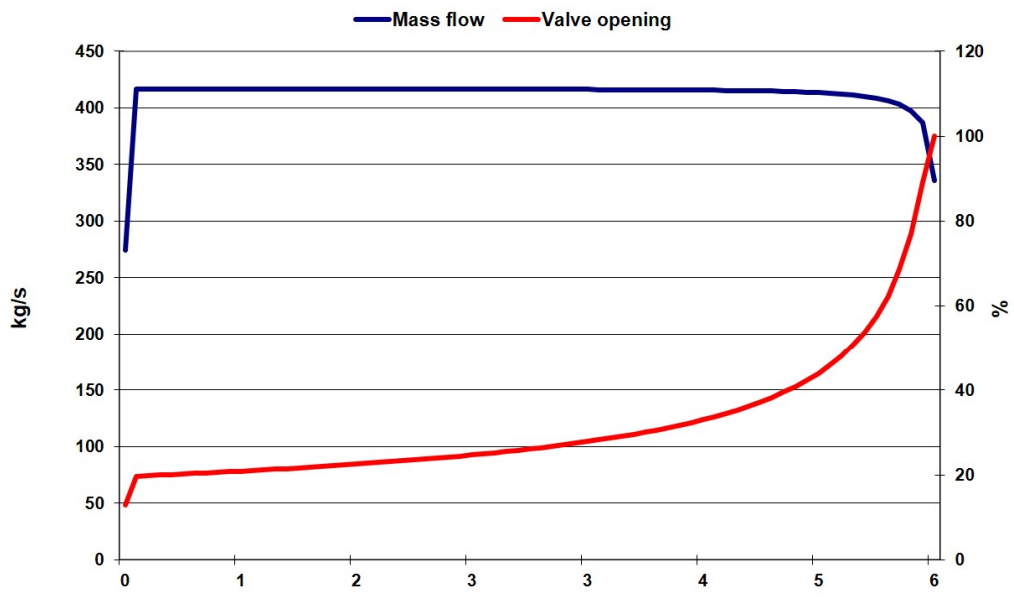

Time, $\mathbf{h}$

Fig. 4. Mass flow of the air released from the cavern and V2 valve openness during discharging. Change of cavern pressure during discharging is shown in Figure 5. 


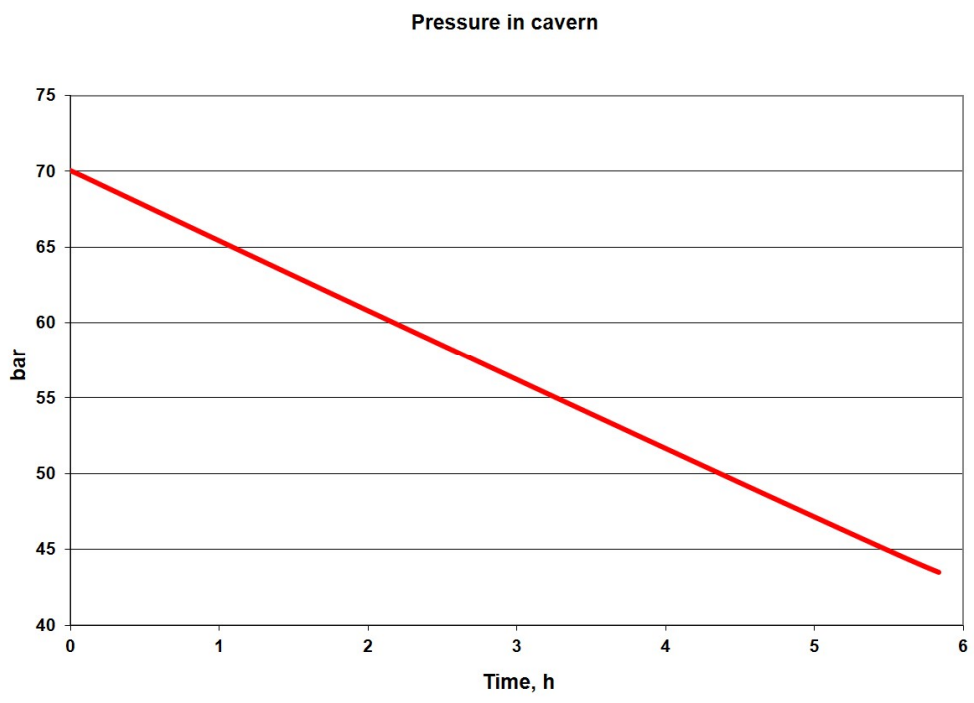

Fig. 5. Changes of pressure inside the cavern during discharging.

Efficiency values for the modelled CAES system are shown in Table 2.

Table 2. Efficiency of the modelled CAES system according to equations (11-14).

\begin{tabular}{|c|c|}
\hline Efficiency & Value, $\%$ \\
\hline$\eta_{C A E S I}$ & 39.77 \\
\hline$\eta_{C A E S I I}$ & -2.02 \\
\hline$\eta_{C A E S I I I}$ & 23.76 \\
\hline$\eta_{C A E S I V}$ & 43.83 \\
\hline
\end{tabular}

\section{Discussion}

The non-linear course of the cavern charging process can be seen in the example of the mass flow (Figure 3). Non-linearity could also be seen for low pressure values (below normal operation of cavern). A similar relationship occurs in the case of pressure when emptying the storage (Figure 5).

During the unloading of the cavern (Figure 4), the mass flow is constant due to the operation of the control system changing the setting of the V2 valve. The curve showing this parameter is highly non-linear.

CAES system presented in this article has a relatively small efficiency according to all four definitions (11-14).

According to the second efficiency definition (12), if the energy consumed by the compressor is larger than the energy produced by the turbine, the result is negative.

For the case of modelled system the most representative is first definition.

\section{Conclusions}

Presented CAES system has a relatively low efficiency, which according to the first definition is only $39.77 \%$. This is due to the absence of a regenerative heat exchanger as used at 
McIntosh plant. The thermal configuration of the modelled CAES plant is modelled after the Huntorf facility, where this component was omitted intentionally to achieve possibly short power plant start-up time. Low efficiencies of conventional CAES systems are also attributable to the fact that in their case heat generated in the process of compression is lost to the environment. It seems that this problem may be solved by adiabatic CAES systems, where the compression heat is stored in thermal oil or pebble bed storage. This recovered heat is then utilised during the expansion process in the turbine. Thanks to this an adiabatic CAES system would not require a combustor. Unfortunately this kind of technology has not yet been used in practical applications.

\section{References}

1. K. Badyda, J. Milewski, Compressed air storage systems as a peak looping power station in Polish conditions, Proceeding of International Conference on Power Engineering, ICOPE 2009 (2009)

2. K. Badyda, J. Milewski, Magazynowanie energii z wykorzystaniem układów CAES. Współczesne problemy energetyki gazowej i gazownictwa. IV Konferencja Energetyka Gazowa [Energy storage using CAES systems. Contemporary problems of gas energy and gas industry. The 4th Gas Power Engineering Conference]. Wydawnictwo Instytutu Techniki Cieplnej Politechniki Śląskiej, Gliwice (pp. 371-388) (2009)

3. K. Badyda, J. Milewski, Thermodynamic analysis of compressed air energy storage working conditions, Archives of Energetics, 42(1), 53-68 (2012)

4. F. Crotogino, K.-U. Mohmeyer, R. Scharf, Huntorf CAES: More than 20 years of successful operation, Orlando, Florida, USA. (2001)

5. A. Gajewski, A. Wójcicki, Międzynarodowy projekt CASTOR a problematyka sekwestracji, czyli ujmowania i magazynowania CO2 w Polsce [International Project CASTOR and the problem of sequestration, or capture and storage of $\mathrm{CO} 2$ in Poland], Przegląd Geologiczny, 54(4), 270-272 (2005)

6. J. E. Mason, C. L. Archer, Baseload electricity from wind via compressed air energy storage (CAES), Renewable and Sustainable Energy Reviews, 16(2), 1099-1109 (2012)

7. H. Lund, G. Salgi, B. Elmegaard, A. N. Andersen, Optimal operation strategies of compressed air energy storage (CAES) on electricity spot markets with fluctuating prices, Applied Thermal Engineering, 29(5), 799-806 (2009)

8. X. Luo, J. Wang, M. Dooner, J. Clarke, C. Krupke, Overview of current development in compressed air energy storage technology, Energy Procedia, 62, 603-611 (2014)

9. M. Satkin, Y. Noorollahi, M. Abbaspour, H. Yousefi, Multi criteria site selection model for wind-compressed air energy storage power plants in Iran, Renewable and Sustainable Energy Reviews, 32, 579-590 (2014)

10. A. Yucekaya, The operational economics of compressed air energy storage systems under uncertainty, Renewable and Sustainable Energy Reviews, 22, 298-305 (2013)

11. J. Kotowicz, M. Jurczyk, Wyznaczenie sprawności diabatycznych instalacji CAES [Efficiency of diabatic CAES instalation], Rynek Energii, 119(4), 49-56 (2015)

12. W. Liu, L. Liu, L. Zhou, J. Huang, Y. Zhang, G. Xu, Y. Yang, Analysis and optimization of a compressed air energy storage-combined cycle system. Entropy, 16(6), 3103-3120 (2014)

13. P. Zhao, J. Wang, Y. Dai, Thermodynamic analysis of an integrated energy system based on compressed air energy storage (CAES) system and Kalina cycle, Energy Conversion and Management, 98, 161-172 (2015)

14. N. M. Jubeh, Y. S. H. Najjar, Green solution for power generation by adoption of adiabatic CAES system, Applied Thermal Engineering, 44, 85-89 (2012) 
15. E. Barbour, D. Mignard, Y. Ding, Y. Li, Adiabatic Compressed Air Energy Storage with packed bed thermal energy storage, Applied Energy, 155, 804-815 (2015)

16. D. Wolf, M. Budt, LTA-CAES-a low-temperature approach to adiabatic compressed air energy storage, Applied Energy, 125, 158-164 (2014)

17. F. De Bosio, V. Verda, Thermoeconomic analysis of a Compressed Air Energy Storage (CAES) system integrated with a wind power plant in the framework of the IPEX Market, Applied Energy, 152, 173-182 (2015)

18. E. Jannelli, M. Minutillo, A. L. Lavadera, G. Falcucci, A small-scale CAES (compressed air energy storage) system for stand-alone renewable energy power plant for a radio base station: A sizing-design methodology, Energy, 78, 313-322 (2014)

19. B. Kantharaj, S. Garvey, A. Pimm, Thermodynamic analysis of a hybrid energy storage system based on compressed air and liquid air. Sustainable Energy Technologies and Assessments, 11, 159-164 (2014)

20. B. Kantharaj, S. Garvey, A. Pimm, Compressed air energy storage with liquid air capacity extension, Applied Energy, 157, 152-164 (2015)

21. P. Krawczyk, Ł. Szabłowski, K. Badyda, S. Karellas, E. Kakaras, Impact of selected parameters on performance of the Adiabatic Liquid Air Energy Storage system, Journal of Power Technologies, 96(4), 238-244 (2016)

22. P. Krawczyk, Ł. Szabłowski, S. Karellas, E. Kakaras, K. Badyda, Comparative thermodynamic analysis of compressed air and liquid air energy storage systems, Energy, 142, 46-54 (2018)

23. L. Szablowski, P. Krawczyk, K. Badyda, S. Karellas, E. Kakaras, W. Bujalski, Energy and exergy analysis of adiabatic compressed air energy storage system, Energy, 138, 1218 (2017)

24. J. Milewski, K. Badyda, Ł. Szabłowski, Compressed Air Energy Storage Systems, Journal of Power Technologies, 96(4), 245-260 (2016)

25. HYSYS 3.2 Dynamic Modeling. Hyprotech (2003)

26. HYSYS 3.2 Operations Guide (2003)

27. Ł. Szabłowski, J. Milewski, Dynamic analysis of compressed air energy storage in the car. Journal of Power Technologies, 91(1), 23-36 (2011)

28. P. Denholm, G. L. Kulcinski, Life cycle energy requirements and greenhouse gas emissions from large scale energy storage systems, Energy Conversion and Management, 45(13), 2153-2172 (2004) 